\title{
Estudo da Radiação na areia da praia da Bacutia
}

\author{
Calheiro, D.S. ${ }^{1 *}$; Passamai, Jr.J.L. ${ }^{1}$ \\ 1 Departamento de Química e Física, Universidade Federal do Espírito Santo, Alegre, ES, Brasil. \\ 2 Departamento de Física, Universidade Federal do Espírito Santo, Vitória, ES, Brasil.
}

*e-mail: danielcalheiro@gmail.com

\section{Resumo}

A praia da Bacutia em Guarapari/ES apresenta traços de radioatividade. Sendo assim, foi feito em toda a extensão da faixa de areia um levantamento radiométrico durante três meses a cada 15 dias aproximadamente e foi possível observar que na extensão da praia na faixa da areia a radioatividade movimenta-se com o auxílio da maré, para a realização das medidas foi utilizado um contador Geiger e um ciclocomputador, adotamos o sentido norte-sul para efetuar as medidas, pode-se concluir que existe uma movimentação da radiação durante os meses do ano ao longo de toda praia.

\begin{abstract}
The beach Bacutia in Guarapari / ES presents radioactivity traits. Thus, it was made throughout the length of the strip of sand one radiometric survey for three months every 15 days or so and it was observed that the length of the beach on the sand track radioactivity moves with the help of the tide, for realization of measures was used a Geiger counter, and a cycling computer, we take the north-south direction to carry out the measures, it can be concluded that there is a movement of radiation during the months of the year along the entire beach.
\end{abstract}

Keywords (Palavras chaves): Monazita, Radioatividade, Óxido de Tório.

\section{Introdução}

No presente trabalho foi feito medição da radioatividade da areia da praia da Bacutia. Pode ser observada a olho nu, uma pequena faixa escura de areia que foi movimentada pela maré ao longo de toda faixa de areia utilizada pelos banhistas.

Foi possível fazer a medida de radioatividade a cada 15 adias aproximadamente durante os meses de Março de 2016 até Maio de 2016.

\section{Apresentação dos resultados}

Após a primeira medida realizada, foi feita foi possível constatar que tivemos picos de intensidade chegando a $0,8 \mathrm{~Bq}$ próximo de 80 metros iniciais da extensão da praia.

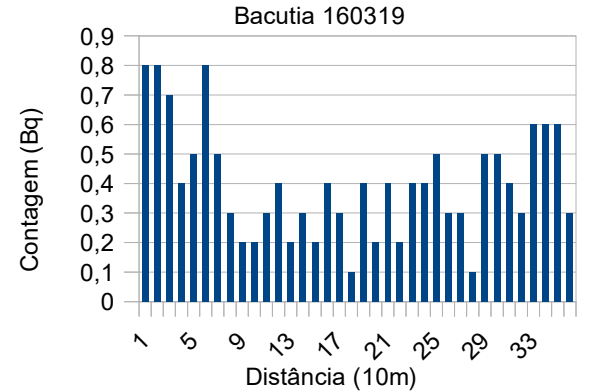

Fizemos uma segunda medida e verificamos que os picos da medida anterior ficaram mais estreitos e aumentaram de intensidade na mesma faixa de 80 metros iniciais.

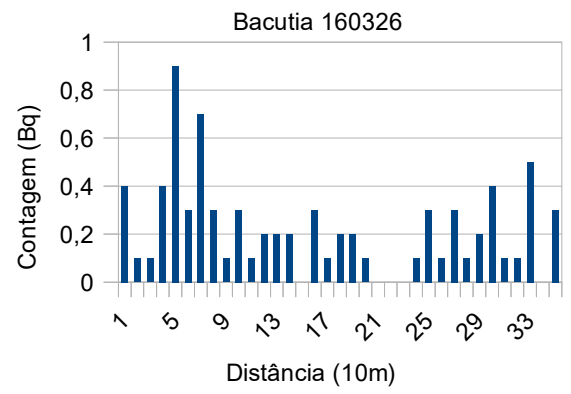


Na próxima medida realizada foi verificado um deslocamento da radiação para os primeiros 50 metros iniciais da faixa de areia, também foi visível um aumento dos picos em 180 metros e 340 metros aproximadamente.

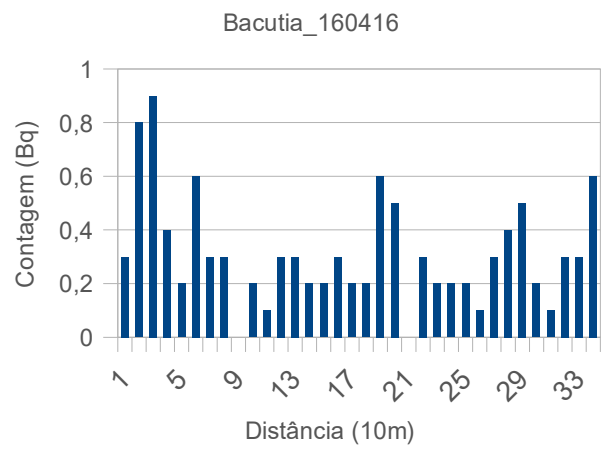

Verificamos na medida seguinte aumento significativo de um pico de radiação em aproximadamente 80 metros passando de $1 \mathrm{~Bq}$.

Bacutia 160430

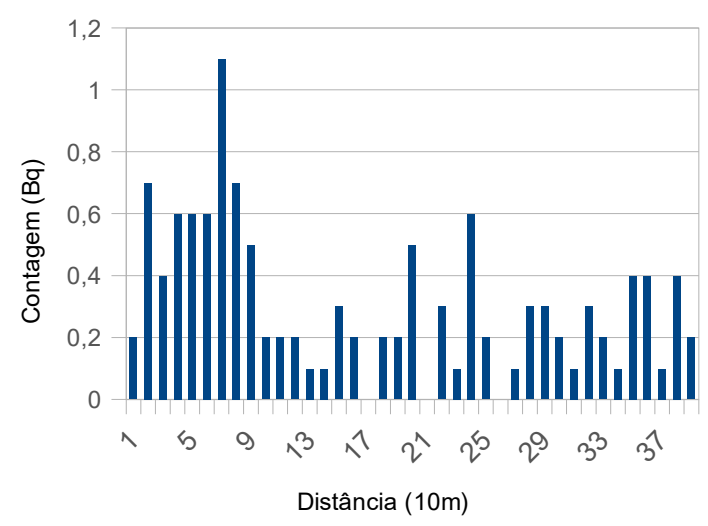

$\mathrm{Na}$ medida do dia 15/05/16 houve um crescimento do pico de radioatividade nos primeiros 10 metros iniciais da faixa de areia e um crescimento dos picos de radioatividade entre 290 e 320 metros.

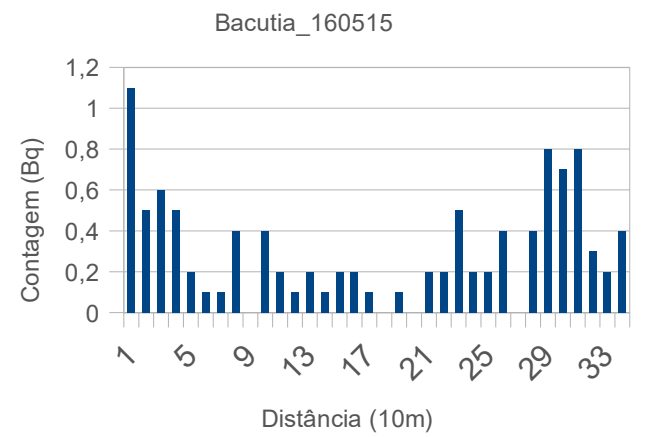

$\mathrm{Na}$ última medida realizada em 26/05/16, hou uma mudança brusca nos picos de radiação, nos primeiros 50 metros caiu à intensidade e houve um acréscimo dos picos de radiação entre 290 e 320 metros.

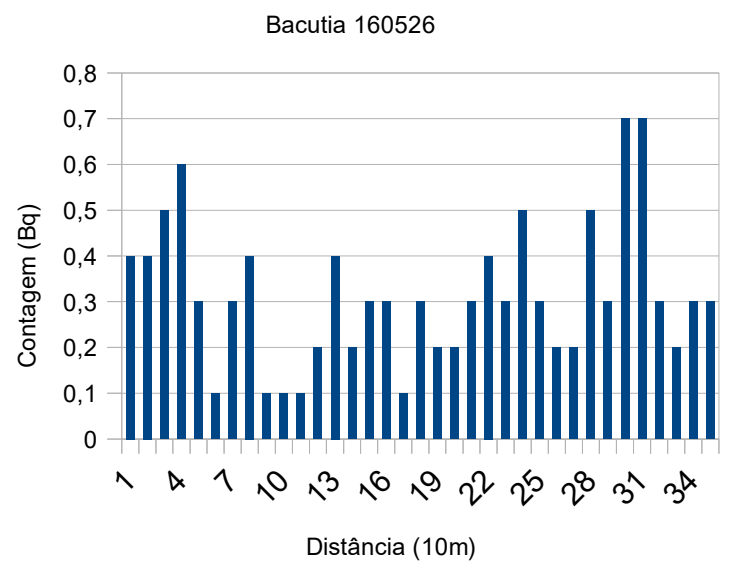

\section{Conclusão}

Durante a realização destas medidas foi possível constatar a variação da intensidade da radiação presente na faixa de areia utilizada pelos banhistas. Nossos estudos prosseguem para acompanhar o movimento da faixa radioativa na praia da Bacutia.

\section{Referências}

FUJINAMI, N.; T. KOGA, T.; MORISHIMA. H. EXTERNAL EXPOUSURE RATES FROM TERRESTRIAL RADIANTION AT GUARAPARI AND MEAIPE IN BRAZIL. 1999.

VASCONCELOS, D.C, et al. MODELLING NATURAL RADIOACTIVITY IN SAND BEACHES OF GUARAPARI, ESPÍRITO SANTO STATE, BRAZIL. 2013 